\title{
NODULAÇÃO, FIXAÇÃO DE NITROGÊNIO E PRODUÇÃO DE MATÉRIA SECA DE ALFAFA EM RESPOSTA A DOSES DE CALCÁRIO, COM DIFERENTES RELAÇÕES CÁLCIO:MAGNÉSIO
}

\author{
NODULATION, NITROGEN FIXATION AND ALFALFA DRY MATTER \\ PRODUCTION AS AFFECTED BY RATES OF LIMESTONE WITH \\ DIFFERENT CALCIUM:MAGNESIUM RATIOS APPLYED
}

\author{
Fernando Teixeira Gomes ${ }^{1}$ Arnaldo Chaer Borges ${ }^{2}$ Júlio César Lima Neves ${ }^{3}$ \\ Paulo Cezar Rezende Fontes ${ }^{4}$
}

RESUMO

Altas concentrações de alumínio reduzem a eficência da nodulação e da fixação biológica do nitrogênio atmosférico em leguminosas. O presente ensaio foi realizado em casa de vegetação com o objetivo de avaliar a necessidade de calagem para o cultivo da alfafa em LATOSSOLO VERMELHOAMARELO álico, textura argilosa. Também foi avaliado o efeito da relação Ca: $\mathrm{Mg}$ do calcário aplicado ao solo, sobre a nodulação, os teores de nitrogênio e a produção de matéria seca da parte aérea. Os tratamentos consistiram de duas cultivares de alfafa (Flórida 77 e Crioula), quatro doses de calcário (1,2; 2,4; 4,$\left.8 ; 7,2 t \mathrm{ha}^{-1}\right)$ e cinco relações percentuais estequiométricas entre $\mathrm{Ca}$ e Mg (100:0; 75:25; 50:50; 25:75; 0:100), em delineamento fatorial inteiramente casualizado, com quatro repetições. A nodulação e os teores de nitrogênio na parte aérea aumentaram com a adição de doses crescentes de calcário ao solo. A produção de matéria seca da parte aérea das duas cultivares aumentou em função do aumento das doses de calcário, sendo que somente o cultivar Flórida 77 apresentou diferenças significativas entre as relações Ca:Mg. A relação 100:0 foi a que rendeu maior produção de matéria seca da parte aérea.

Palavras-chave: Medicago sativa, eficiência da nodulação, calagem.

\section{SUMMARY}

High aluminum concentrations decrease the nodulation potential, hence the biological atmosferic nitrogen fixation of legume. This greenhouse experiment was aimed to evaluate the effects of limestone applyet on alfalfa cultivation in alic YELLOWISH RED LATOSOL SOIL, clay texture. It evaluated the ideal $\mathrm{Ca}^{2+}$ and $\mathrm{Mg}^{2+}$ ratios in neutralizing soil acidity. Treatments were two alfalfa cultivars (Florida 77 and Creoula), four limestone rates $\left(1.2 ; 2.4 ; 4.8 ; 7.2\right.$ t.ha $\left.{ }^{-1}\right)$ and five stoichiometric percentual ratios Ca:Mg between (100:0; 75:25; $50: 50 ; 25: 75 ; 0: 100)$, in a factorial set up into a completely randomized design with four replications. Nodulation and nitrogen contents in the shoots increased with increased limestone rates. Shoots dry matter production of both cultivars increased with the rates of limestone, but only the cultivar Florida 77 showed significant differences among Ca:Mg ratios.

Key words: Medicago sativa, nodulation efficiency, liming.

\section{INTRODUÇÃO}

A toxidez causada pelo alumínio (A $\ell$ ) é um dos mais importantes fatores que limitam o crescimento das plantas em solos ácidos, principalmente em $\mathrm{pH}$ abaixo de 5,0. O A $\ell$ acumulase, preferencialmente, no sistema radicular das plantas, sendo pequena a quantidade translocada para a parte aérea (MASSOT et al., 1992). O efeito do alumínio trocável $\left(\mathrm{A} \ell^{3+}\right)$ em níveis tóxicos sobre o desenvolvimento do sistema radicular se caracteriza pela inibição do alongamento da raiz principal e pelo engrossamento das pontas das

\footnotetext{
${ }^{1}$ Biólogo, DS, Fisiologia Vegetal, Universidade Federal de Viçosa (UFV), Viçosa, MG. E-mail: ftgomes@bol.com.br. Autor para correspondência.

${ }^{2}$ Engenheiro Agrônomo, PhD., Professor Titular, Departamento de Microbiologia, UFV. E-mail: chaer@mail.ufv.br.

${ }^{3}$ Engenheiro Agrônomo, Doutor, Professor Adjunto, Departamento de Solos, UFV. E-mail: julio@ solos.ufv.br.

${ }^{4}$ Engenheiro Agrônomo, PhD., Professor Titular, Departamento de Fitotecnia, UFV. E-mail: pacerefo@mail.ufv.br.
} 
raízes, resultando em exploração de menor volume de solo pelas plantas, redução na absorção de nutrientes e no aproveitamento da água do solo.

A alfafa (Medicago sativa) reúne algumas das mais desejadas características de plantas forrageiras, como excelente palatabilidade, alta digestibilidade e elevado valor nutritivo, sendo rica em proteínas, fósforo, cálcio, potássio e vitaminas A, B, C, E e K (MICHAUD et al., 1988). Como a maioria das leguminosas, ela é sensível à acidez do solo.

O potencial de fixação do nitrogênio atmosférico $\left(\mathrm{N}_{2}\right)$ da associação simbiótica Medicago sativa e Sinorhizobium meliloti é de aproximadamente $200 \mathrm{~kg}$ de $\mathrm{N} \mathrm{ha}^{-1} \cdot \mathrm{ano}^{-1}$, assegurando o suprimento do nitrogênio requerido pela planta, dispensando, na maioria das vezes, a aplicação de adubos nitrogenados, evitando os problemas ambientais resultantes do uso inadequado destes fertilizantes. As variações na fixação do $\mathrm{N}_{2}$ resultam principalmente de práticas de manejo em vários climas e condições de fertilidade do solo (VANCE \& HEICHEL, 1991).

A alfafa é muito exigente quanto ao $\mathrm{pH}$ do solo, situando-se o ótimo na faixa de 6,0 a 7,5 (BALIGAR $\boldsymbol{e t}$ al., 1989), embora a planta apresente desenvolvimento normal quando cultivada em solução nutritiva sem $\mathrm{A} \ell$, mesmo em $\mathrm{pH} 4,5$ (RECHCIGL et al., 1986), indicando que o fator mais limitante ao desenvolvimento desta cultura é o elevado teor de $\mathrm{A} \ell^{3+}$ do solo e não o baixo $\mathrm{pH}$. A elevação do $\mathrm{pH}$ do solo estaria mais relacionada com o aumento na disponibilidade de elementos essenciais à planta. Assim, a calagem é considerada prática fundamental para elevar o $\mathrm{pH}$ do solo e neutralizar ou reduzir os efeitos tóxicos do $\mathrm{A} \ell^{3+} \mathrm{e}$ do manganês (NUERNBERG $\boldsymbol{e t}$ al., 1990; SU \& EVANS, 1996).

Diversos estudos têm mostrado os efeitos benéficos da calagem sobre a nodulação, absorção de nutrientes e a produção de matéria seca da parte aérea, em várias espécies vegetais (POOLPIPATANA \& HUE, 1994; PHILIP et al., 1995; REID, 1996). Em um ensaio utilizando LATOSSOLO VERMELHO-ESCURO distrófico, foi avaliado o efeito da adição de doses de calcário ao solo com diferentes relações $\mathrm{Ca}: \mathrm{Mg}$, sobre o comportamento da alfafa cv. Crioula. Os autores observaram respostas significativas no aumento da produção de matéria seca, com o incremento das doses de calcário. No entanto, não foram observadas respostas significativas às relações $\mathrm{Ca}: \mathrm{Mg}$ (MOREIRA et al., 1999). Nas condições de cerrado, também foi observado que a alfafa continuou respondendo à aplicação de calcário ao solo (KORNELIUS \& RITCHEY, 1992).

O objetivo desse estudo foi o de investigar a necessidade de calcário em um LATOSSOLO VERMELHO-AMARELO álico e a relação estequiométrica $\mathrm{Ca}: \mathrm{Mg}$ mais adequada à nodulação, fixação do $\mathrm{N}_{2}$ e produção de matéria seca do sistema simbiótico Medicago sativa Sinorhizobium meliloti.

\section{MATERIAL E MÉTODOS}

O experimento foi conduzido em casa de vegetação em 1995, e o solo utilizado foi coletado da camada superficial $(0-20 \mathrm{~cm})$ de LATOSSOLO VERMELHO-AMARELO álico, textura argilosa, localizado no município de Viçosa - MG, com as seguintes características químicas: $\mathrm{pH}_{\text {(água) }} 4,6 ; 2,5$ e 46,8mg de $\mathrm{P}$ e $\mathrm{K} \mathrm{dm}^{-3}$ de solo, respectivamente; 0,6; 0,2 e $1,2 \mathrm{cmo} \ell_{\mathrm{c}}$ de $\mathrm{Ca}^{2+}, \mathrm{Mg}^{2+}$ e $\mathrm{A} \ell^{3+} \mathrm{dm}^{-3}$ de solo, respectivamente e $\mathrm{V}=9,7 \%$. Os tratamentos consistiram de duas cultivares de alfafa, (Flórida 77 e Crioula), quatro doses de calcário calculadas com base no $\mathrm{A} \ell^{3+}$ do solo (KAMPRATH, 1967), multiplicadas pelos fatores: 1,$0 ; 2,0 ; 4,0$ e 6,0 e cinco relações percentuais estequiométricas de Ca:Mg: 100:0, 75:25, 50:50, 25:75 e 0:100. Utilizouse um esquema fatorial em delineamento inteiramente casualizado, com quatro repetições.

As fontes de cálcio e magnésio utilizadas foram o $\mathrm{CaCO}_{3}$ e o $\mathrm{MgCO}_{3}$ (pa), respectivamente, misturados em subamostras de $12 \mathrm{dm}^{3}$ de solo seco ao ar e passadas em peneira com malha de $2 \mathrm{~mm}$. Em seguida foi adicionada água destilada para elevar a umidade a $60 \%$ da capacidade de campo (SILVA, 1986). O solo foi incubado em recipientes de plástico até a obtenção de valores de $\mathrm{pH}$ constantes, e posteriormente o solo de cada tratamento foi seco ao ar e passado em peneira com malha de $2 \mathrm{~mm}$. Cada subamostra foi dividida em porções de $2,8 \mathrm{dm}^{3}$ de solo e novamente acondicionada em vasos de plástico.

Soluções de macronutrientes foram misturadas a cada subamostra antes da semeadura de modo a fornecer, 60, 40 e $450 \mathrm{mg}$ de $\mathrm{K}, \mathrm{S} \mathrm{e} \mathrm{P} \mathrm{dm}^{-3}$ de solo, respectivamente. Soluções de micronutrientes foram parceladas eqüitativamente em duas aplicações, visando a fornecer o total de 0,813 , 3,664, 4,0, 1,329, 0,15 e 1,556mg de B, Mn, Zn, Cu, Mo e $\mathrm{Fe} \mathrm{dm}^{-3}$ de solo, respectivamente (ALVAREZ, 1974).

As sementes foram fornecidas pela Embrapa Gado de Leite, Juiz de Fora, MG; após a desinfestação superficial por imersão em etanol $75 \%$ 
por 1 minuto e em peróxido de hidrogênio $6 \%(\mathrm{v}: \mathrm{v})$ por 10 minutos, seguida de lavagem em água destilada estéril (VINCENT, 1970), foram inoculadas com Sinorhizobium meliloti e imediatamente semeadas nos vasos. Após sete dias de emergência foi feito um desbaste, deixando-se três plântulas por vaso.

A irrigação foi efetuada com água destilada, diariamente, procurando-se manter a umidade do solo próxima a $60 \%$ da capacidade de campo, por pesagem dos vasos. Setenta dias após a semeadura, a parte aérea foi cortada a $8 \mathrm{~cm}$ do solo e colocada em sacos de papel para a secagem a $65^{\circ} \mathrm{C}$ por 72 horas. A colheita do experimento coincidiu com o florescimento completo das plantas. Neste mesmo período o sistema radicular foi coletado, lavado em água de torneira e os nódulos foram destacados e contados. As determinações de nitrogênio na matéria seca da parte aérea foram realizadas após a digestão sulfúrica, pelo método colorimétrico de Nessler (CATALDO et al., 1974).

Os dados obtidos no experimento foram estudados pela análise de variância, efetuando-se o desdobramento dos graus de liberdade para cultivares, dentro das doses de calcário e das relações estequiométricas $\mathrm{Ca}: \mathrm{Mg}$. Para cada cultivar, as doses de calcário e as relações estequiométricas $\mathrm{Ca}: \mathrm{Mg}$ foram comparadas pela análise de regressão, e os modelos foram selecionados com base na significância dos coeficientes de regressão pelo teste " $\mathrm{t}$ ", posteriormente considerando o maior valor do coeficiente de determinação $\left(r^{2}\right)$. Para o número de nódulos, as médias dos tratamentos foram comparadas pelo teste de Tukey a 5\% de significância, utilizando o programa de estatística SAS Statistical Analysis System.

\section{RESULTADOS E DISCUSSÃO}

As relações estequiométricas entre $\mathrm{Ca}$ e $\mathrm{Mg}$ nas quatro doses de calcário não afetaram os valores de $\mathrm{pH}$ do solo (Tabela 1). As doses de calcário correspondentes a 4,8 e 7,2t.ha ${ }^{-1}$ foram suficientes para elevar o $\mathrm{pH}$ a valores maiores ou iguais a 5,1 e neutralizar o $\mathrm{A} \ell^{3+}$ do solo (Tabela 1). De modo geral, o $\mathrm{A} \ell^{3+}$ desaparece em solos quando o pH é elevado a valores próximos a 5,5 (McCLEAN \& KAMPRATH, 1965) e em solos argilosos a neutralização do $\mathrm{A} \ell^{3+}$ pode ocorrer em valores de $\mathrm{pH}$ ainda mais baixos que 5,5 (RAIJ, 1983). Embora os valores de $\mathrm{pH}$ do solo não tenham alcançado a faixa de 6,0 a 7,5, considerada ótima para o cultivo da alfafa (BALIGAR, 1989), a redução nos teores de $\mathrm{A} \ell^{3+}$ com o incremento nas doses de calcário aplicado ao solo contribuiu para aumentar a produção das plantas de alfafa.

Não foram efetuadas as determinações de nitrogênio e de matéria seca da parte aérea das plantas do tratamento com a relação 0:100, em razão da morte das plântulas aos 20 dias após a semeadura no tratamento correspondente a 7,2t de calcário ha ${ }^{-1}$. Provavelmente, o grande desbalanço entre a concentração de $\mathrm{Ca}^{2+}$ e $\mathrm{Mg}^{2+}$ tenha provocado a morte dessas plantas.

O número de nódulos nas duas cultivares, de modo geral, aumentou em resposta à elevação da quantidade de calcário (Tabela 2) e diminuiu com a maior concentração de $\mathrm{Mg}^{2+}$ nas relações estudadas, atingindo até a ausência de nódulos.

A ausência de nódulos nos tratamentos em que o cálcio não foi aplicado (Tabela 2), demonstra a importância deste nutriente no processo de nodulação, pois o mesmo apresenta papel relevante na atividade de enzimas que promovem a ligação do rizóbio aos pêlos radiculares. Com o valor de $\mathrm{pH}$ de 5,3, na dose de 4,8t de calcário ha ${ }^{-1}$, na relação 0:100 (Tabela 1), o teor de $\mathrm{Ca}^{2+}$ no solo era de $0,5 \mathrm{cmo} \ell_{\mathrm{c}} \cdot \mathrm{dm}^{-3}$, não sendo suficiente para promover a nodulação. Esse fato ressalta a necessidade de calagem em solos ácidos com o objetivo de fornecer também o cálcio para um melhor estabelecimento da associação simbiótica entre Medicago sativa e Sinorhizobium meliloti. O efeito positivo da calagem sobre o número de nódulos e também sobre a atividade da nitrogenase já foi observado em alfafa por HARTEL \& BOUTON (1989), PIJNENBORG \& LIE (1990) e REID (1996).

Os teores de nitrogênio na matéria seca da parte aérea das duas cultivares, nas doses de calcário em cada relação estequiométrica $\mathrm{Ca}: \mathrm{Mg}$ ajustaramse melhor ao modelo quadrático base raiz quadrada de regressão (Figura 1A e 1B). Os teores máximos estimados de nitrogênio, nas médias das relações estequiométricas Ca:Mg, seriam obtidos com 5,34 e $4,73 \mathrm{t}$ de calcário ha $^{-1}$ para as cultivares Flórida 77 e Crioula, respectivamente.

Os teores de nitrogênio na matéria seca da parte aérea foram proporcionais à quantidade de calcário adicionado ao solo, variando de 1,03 a 3,95dag. $\mathrm{kg}^{-1}$. Resultados similares foram obtidos em soja por MUCHOVEJ et al., (1986). KELLING \& MATOCHA (1990) obtiveram teores de nitrogênio na matéria seca da parte aérea de plantas de alfafa variando de 2,6 a 3,7dag. $\mathrm{kg}^{-1}$. Portanto, os teores obtidos no presente estudo podem ser considerados satisfatórios, exceto da menor dose de calcário em todas as relações Ca:Mg (Figuras $1 \mathrm{~A}$ e 1B). 
Tabela 1 - Características químicas do solo ${ }^{1 /}$, determinadas aos noventa dias após o início da incubação.

\begin{tabular}{|c|c|c|c|c|c|}
\hline $\begin{array}{l}\text { Doses de } \\
\text { calcário }\end{array}$ & $\begin{array}{c}\text { Relações este- } \\
\text { quiométricas } \\
\text { Ca:Mg }\end{array}$ & $\begin{array}{c}\text { pH água } \\
(1: 2,5)\end{array}$ & $\mathrm{Ca}^{2+} 1 /$ & $\mathrm{Mg}^{2+} 1 /$ & $\mathrm{A} \ell^{3-} 1 /$ \\
\hline t.há ${ }^{-1}$ & $\%$ & & \multicolumn{3}{|c|}{$\mathrm{cmo} \ell_{\mathrm{c}} \cdot \mathrm{dm}^{-3}$ de solo } \\
\hline \multirow{5}{*}{1,2} & 100:0 & 4,6 & 1,8 & 0,3 & 0,6 \\
\hline & $75: 25$ & 4,6 & 1,4 & 0,3 & 0,5 \\
\hline & $50: 50$ & 4,6 & 1,2 & 0,5 & 0,5 \\
\hline & $25: 75$ & 4,6 & 0,9 & 0,7 & 0,5 \\
\hline & $0: 100$ & 4,7 & 0,6 & 0,8 & 0,5 \\
\hline \multirow{5}{*}{2,4} & $100: 0$ & 4,6 & 2,7 & 0,2 & 0,3 \\
\hline & $75: 25$ & 4,7 & 2,1 & 0,5 & 0,3 \\
\hline & $50: 50$ & 4,6 & 1,6 & 0,7 & 0,3 \\
\hline & $25: 75$ & 4,6 & 1,4 & 1,0 & 0,3 \\
\hline & $0: 100$ & 4,9 & 0,6 & 1,0 & 0,3 \\
\hline \multirow{5}{*}{4,8} & $100: 0$ & 5,1 & 5,0 & 0,3 & $*$ \\
\hline & $75: 25$ & 5,2 & 3,8 & 1,6 & $*$ \\
\hline & $50: 50$ & 5,1 & 3,2 & 2,1 & $*$ \\
\hline & $25: 75$ & 5,2 & 1,7 & 3,0 & $*$ \\
\hline & $0: 100$ & 5,3 & 0,5 & 3,9 & $*$ \\
\hline \multirow{5}{*}{7,2} & 100:0 & 5,6 & 5,8 & 0,4 & $*$ \\
\hline & $75: 25$ & 5,5 & 5,6 & 1,7 & $*$ \\
\hline & $50: 50$ & 5,6 & 4,4 & 2,8 & $*$ \\
\hline & $25: 75$ & 5,5 & 2,1 & 3,9 & $*$ \\
\hline & $0: 100$ & 5,5 & 0,6 & 5,3 & $*$ \\
\hline
\end{tabular}

1/ $\mathrm{Ca}^{2+}, \mathrm{Mg}^{2+} \mathrm{e} \mathrm{A} \ell^{3+}$ extraídos com KC $\ell$ 1,0 mo $\ell . \ell^{-1}$ (VETTORI, 1969). * Menor que o valor de deteccão.

Tabela 2 - Número de nódulos por vasos das duas cultivares de alfafa, aos setenta dias após a semeadura (média de quatro repetições).

\begin{tabular}{|c|c|c|c|c|c|c|c|c|}
\hline \multirow[b]{2}{*}{$\begin{array}{l}\text { Relações } \\
\mathrm{Ca}: \mathrm{Mg}\end{array}$} & \multicolumn{8}{|c|}{ Doses de calcário (t.há ${ }^{-1}$ ) } \\
\hline & 1,2 & 2,4 & 4,8 & 7,2 & 1,2 & 2,4 & 4,8 & 7,2 \\
\hline & \multicolumn{4}{|c|}{ Flórida 77} & \multicolumn{4}{|c|}{ Crioula } \\
\hline$\%$ & \multicolumn{4}{|c|}{$\mathrm{n}^{\circ}$ vaso $^{-1}$} & \multicolumn{4}{|c|}{$\mathrm{n}^{\circ}$ vaso $^{-1}$} \\
\hline 100:0 & $11 \mathrm{~d}$ & $160 \mathrm{c}$ & $456 \mathrm{~b}$ & $1415 \mathrm{a}$ & $14 d$ & $225 c$ & $503 b$ & $1277 a$ \\
\hline $75: 25$ & $0 \mathrm{~d}$ & $236 c$ & $377 b$ & $1242 \mathrm{a}$ & Od & $114 \mathrm{c}$ & $560 \mathrm{~b}$ & $1049 a$ \\
\hline $50: 50$ & $0 \mathrm{c}$ & $222 b$ & $674 a$ & $700 \mathrm{a}$ & Od & $323 c$ & $758 \mathrm{~b}$ & $1263 a$ \\
\hline $25: 75$ & $0 \mathrm{~d}$ & $92 \mathrm{c}$ & $340 \mathrm{~b}$ & $706 a$ & Od & $274 c$ & $469 b$ & $734 a$ \\
\hline $0: 100$ & 0 & 0 & 0 & 0 & 0 & 0 & 0 & 0 \\
\hline
\end{tabular}

Médias seguidas por letras distintas nas linhas, para cada cultivar, diferem entre si a $5 \%$ de probabilidade pelo teste de Tukey.

$\mathrm{Na}$ relação 100:0, na menor dose de calcário, a pequena nodulação não aumentou os teores de nitrogênio na matéria seca da parte aérea. A coloração esbranquiçada dos nódulos nesse tratamento sugere a ineficiência no processo de fixação do $\mathrm{N}_{2}$ atmosférico.

Nos tratamentos em que foi observada a ausência ou baixa nodulação, os teores de nitrogênio na matéria seca da parte aérea situaram-se na faixa de 1,03 a $1,46 \mathrm{dag} \cdot \mathrm{kg}^{-1}$, abaixo do nível considerado satisfatório para essa espécie (KELLING \& MATOCHA, 1990).

Os grandes aumentos dos números de nódulos em função das doses de calcário (Tabela 2) se relacionaram com os aumentos nos conteúdos de nitrogênio na matéria seca da parte aérea. Uma eficiente fixação do $\mathrm{N}_{2}$ atmosférico pressupõe maior produção de matéria seca da parte aérea, disponibilizando melhor suprimento de carboidratos aos nódulos.

A produção de matéria seca da parte aérea para a cultivar Flórida 77 aumentou de forma linear para as doses de calcário em todas as relações $\mathrm{Ca}: \mathrm{Mg}$ (Figura $2 \mathrm{~A}$ ), demonstrando a sensibilidade desta cultivar às variações nas doses de calcário e em menor escala, às relações estequiométricas de $\mathrm{Ca}: \mathrm{Mg}$. Em alfafa, foram obtidos aumentos significativos na produção de matéria seca da parte aérea em função do aumento na dose de calcário. No entanto, nenhum efeito significativo foi observado entre as diferentes relações $\mathrm{Ca}: \mathrm{Mg}$ aplicadas ao solo (REID, 1996; SU \& EVANS, 1996; MOREIRA et al., 1999). Em razão da maior produção de matéria seca da parte aérea na relação 100:0, a cultivar Flórida 77 mostrou maior sensibilidade ao baixos teores de $\mathrm{Ca}^{2+}$ no solo do que aos de $\mathrm{Mg}^{2+}$. O baixo teor de $\mathrm{Mg}^{2+}$ no solo não prejudicou a produção de matéria seca da parte aérea. A linearidade do modelo indica que maiores doses de calcário do que o aplicado na relação 7,2t.ha ${ }^{-1}$ (Figura 2A) seriam necessárias para a obtenção da produção máxima. Portanto, essa cultivar é altamente exigente em cálcio.

A produção de matéria seca da parte aérea da cultivar Crioula ajustou-se ao modelo quadrático de regressão e foi influenciada apenas pelas doses de calcário, não havendo efeito significativo das relações estequiométricas $\mathrm{Ca}: \mathrm{Mg}$. Por esse modelo a dose de 6,9t de calcário ha ${ }^{-1}$ é adequada para a obtenção da produção máxima (Figura 2B). A ausência de resposta da cultivar Crioula às relações estequiométricas $\mathrm{Ca}: \mathrm{Mg}$ sugere que a mesma seja mais tolerante a baixos níveis de $\mathrm{Ca}^{2+}$ no solo, ao contrário da cultivar Florida 77. Essa característica da cultivar Crioula, provavelmente, deve-se ao fato de ela ter surgido por um processo de seleção 


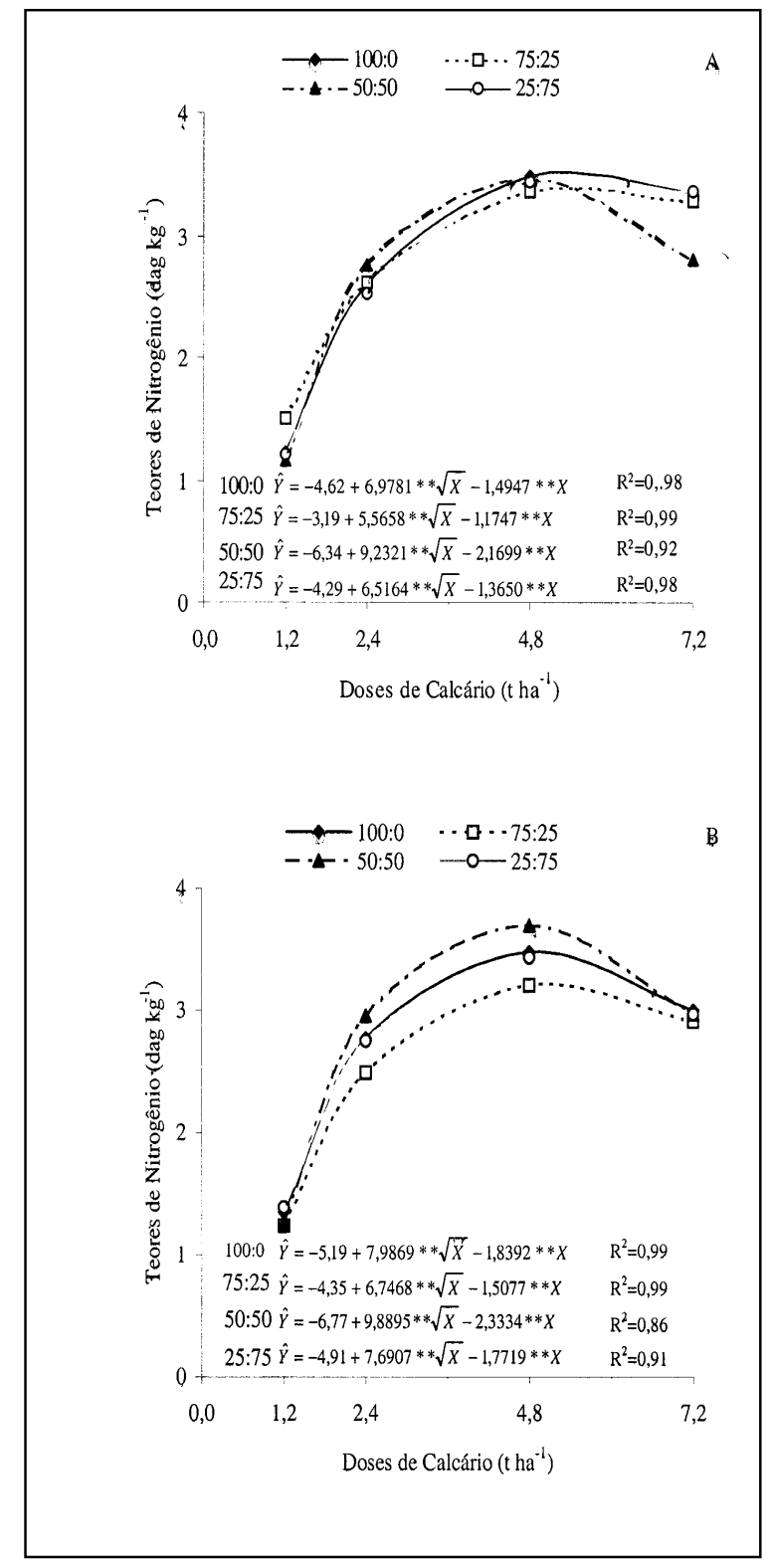

Figura 1 - Teores de nitrogênio na parte aérea das cultivares Flórida 77 (A) e Crioula (B), aos 70 dias após a semeadura em função das doses de corretivo $(\mathrm{X}) \mathrm{e}$ das relações estequiométricas ( $\mathrm{R}$ ) entre $\mathrm{Ca}$ e $\mathrm{Mg}$ aplicados ao solo.

natural, provavelmente no Rio Grande do Sul, sob condições ambientes adversas e solos de baixa fertilidade (HONDA \& HONDA, 1990).

A menor dose de calcário utilizada proporcionou teores de $\mathrm{Ca}^{2+}+\mathrm{Mg}^{2+}$ no solo antes do plantio, variando de 1,4 a $2,1 \mathrm{cmo} \ell_{\mathrm{c}} \cdot \mathrm{dm}^{-3}$ (Tabela 1 ); estes teores são considerados baixos pelo critério da Comissão de Fertilidade do Solo do Estado de Minas Gerais (1999). Pelo critério dessa Comissão, considerando-se a alfafa como cultura exigente em

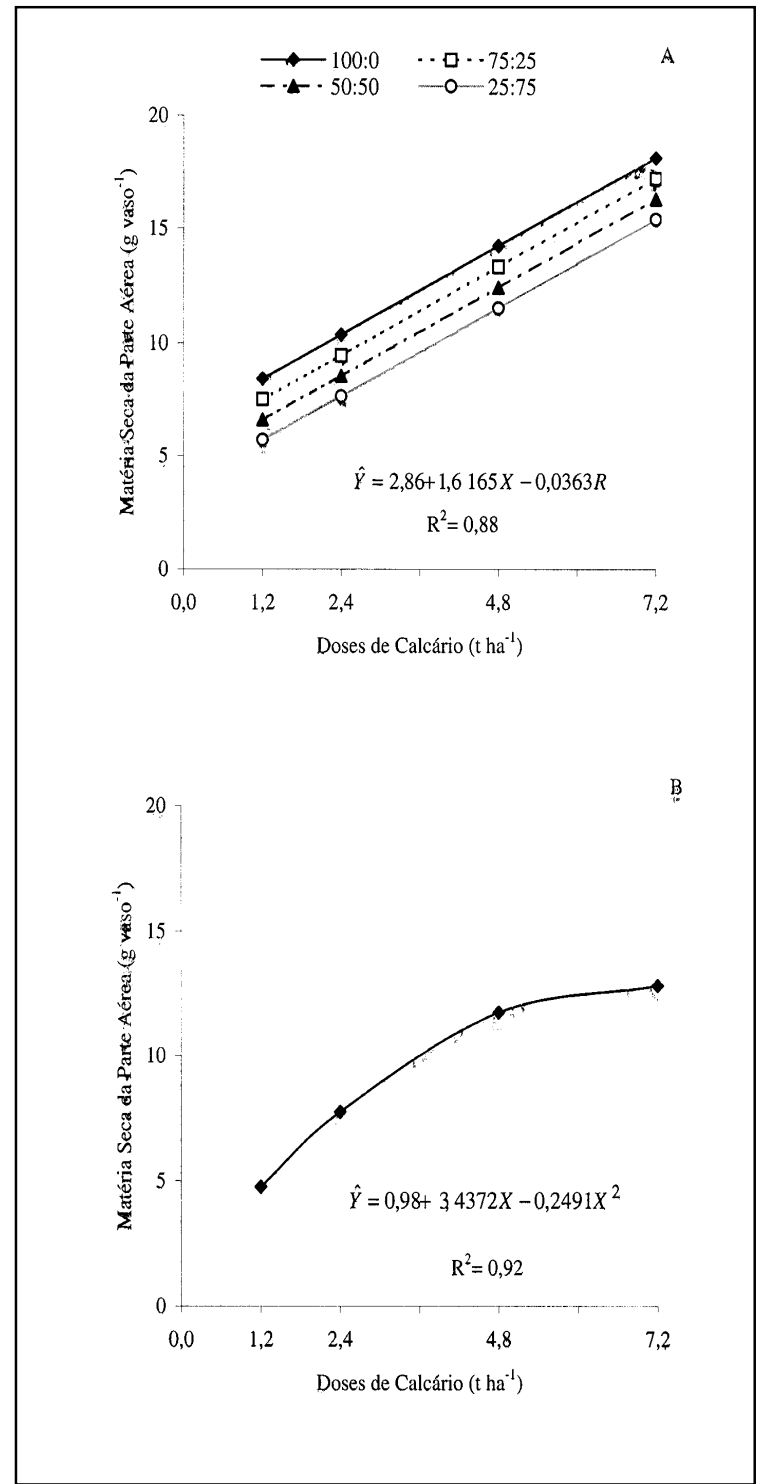

Figura 2 - Matéria seca da parte aérea das cultivares Flórida 77 (A) e Crioula (B) aos 70 dias após a semeadura em função dos níveis de corretivo $(\mathrm{X})$ e das relações estequiométricas ( $\mathrm{R}$ ) entre $\mathrm{Ca}$ e $\mathrm{Mg}$ aplicados no solo.

calagem, deveriam ser aplicados 5,8t de calcário ha ${ }^{-1}$, que proporcionariam aproximadamente $98 \%$ da produção máxima de matéria seca da parte aérea para a cultivar Crioula. Entretanto, para a cultivar Flórida 77, a maior produção de matéria seca da parte aérea foi obtida com a aplicação de 7,2t de calcário ha ${ }^{-1}$.

\section{CONCLUSÕES}

As cultivares de alfafa Flórida 77 e Crioula apresentaram bom desenvolvimento em LATOSSOLO VERMELHO-AMARELO álico,

Ciência Rural, v. 32, n. 6, 2002. 
quando não mais se tem alumínio trocável no solo. As diferentes relações estequiométricas $\mathrm{Ca}: \mathrm{Mg}$ não proporcionaram diferenças nos valores de $\mathrm{pH}$ do solo em nenhuma dose de calcário. A calagem aumentou a produção de matéria seca da parte aérea, a nodulação e os teores de nitrogênio da alfafa. No entanto, somente a cultivar Flórida 77 mostrou sensibilidade às variações nas relações $\mathrm{Ca}: \mathrm{Mg}$, apresentando maior produção de matéria seca na relação 100:0. A cultivar Crioula mostrou maior tolerância aos baixos níveis de $\mathrm{Ca}$ ao solo do que a Flórida 77. A elevada concentração de $\mathrm{Mg}$ na relação $0: 100$, na maior dose de calcário, foi altamente tóxica causando a morte das plantas.

\section{REFERÊNCIAS BIBLIOGRÁFICAS}

ALVAREZ V., H.V. Equilíbrio de formas disponíveis de fósforo e enxofre em dois latossolos de Minas Gerais. Viçosa, MG, 1974. 125p. Dissertação (Mestrado em Solos e Nutrição de Plantas) - Curso de Pós-graduação em Solos e Nutrição de Plantas, Universidade Federal de Viçosa, 1974.

BALIGAR, V.C., ELGIN JR., J.H., FOY, C.D. Variability in alfafa for growth and mineral uptake and efficiency ratios under aluminum stress. Agronomy Journal, Madison, v.81, n.2, p.223-229, 1989

CATALDO, D. A., SCHRADER, L.E., YOUNGS, V.L. Analysis by digeston and colorimetric assay of total nitrogen in plant tissues high in nitrate. Crop Science, Madison, v.14, p.854 $856,1974$.

COMISSÃO DE FERTILIDADE DO SOLO DO ESTADO DE MINAS GERAIS. Recomendação para o uso de calcário e fertilizantes em Minas Gerais. 5. Apr. Viçosa, MG, 1999. 359 p.

HARTEL, P G., BOUTON, J.H. Rhizobium meliloti inoculation of plant alfalfa selected for tolerance to acid, aluminum-rich soils. Plant and Soil, Dordrecht, v.116, n.2, p.283-285, 1989.

HONDA, C.S., HONDA, A.M. Cultura da alfafa. Cambará : IARA, 1990. 245p.

KAMPRATH, E.J. Soil acidity and response to liming. Raleigh : North Carolina State University, Int Soil Testing Serv, 1967. 23p. (Technical Bulletin, 4)

KELLING, K.A., MATOCHA, J.E. Plant analysis as an aid in fertilizing forage crops. In: WESTERMAN, P.L. Soil testing and plant analysis. 3.ed. Madison, Wisconsin, USA: Soil Science Society of American, 1990. p.603-643.

KORNELIUS, E., RITCHEY, K.D. Comportamento da alfafa em diferentes níveis de acidez do solo. Pesquisa Agropecuária Brasileira, Brasília, v.27, n.2, p.241-246, 1992

MASSOT, N., POSCHENRIEDER, C., BARCELÓ, J. Differential response of three bean (Phaseolus vulgaris $\mathbf{L}$.) cultivars to aluminum. Acta Botanica Neerlandica, Oxford, v.41, p.293-298, 1992.

McCLEAN, G.D., KAMPRATH, E.J. Supplying calcium and magnesium for cotton on sandy, low cation exchange capacity soils. Agronomy Journal, Madison, v.57, n.4, p.404-406, 1965.
MICHAUD, R., LECHMAN, W.F., RUMBAUGH, M.D. World distribuition and historical development. In: HANSON, A.A., BARNES, D.K., HILL, R.R. (eds.) Alfalfa and alfalfa improvement. Madison, Wisconsin, USA : American Society of Agronomy, 1988. p.25-91.

MOREIRA, A., CARVALHO, J.G., EVANGELISTA, A.R. Influência da relação cálcio:magnésio do corretivo na nodulação, produção e composição mineral da alfafa. Pesquisa Agropecuária Brasileira, Brasília, v.34, n.2, p.249-255, 1999 .

MUCHOVEJ, R MC. BORGES, AC NOVAIS, R F et al. Effect of liming level and $\mathrm{Ca}: \mathrm{Mg}$ ratios on yield, nitrogen content and nodulation of soyabeans grown in acid cerrado soil. Journal of Soil Science, Oxford, v.37, n.2, p.235-240, 1986.

NUERNBERG, N.J., MILAN, P.A., SILVEIRA, C.A.M. Cultivo, manejo e utilizacão da alfafa. In: NUERNBERG, N.J., MILAN, P.A., SILVEIRA, C.A.M. Manual de produção de alfafa. Florianópolis : EMPASC, 1990. p.15-56.

PHILIP, A., JOSEPH, M., PUNNOOSE, K. I., et al. Effects of liming on nutrient uptake, biomass production and nodulation in Pueraria phaseoloides. Indian Journal of Natural Rubber Research, Kerala, v.8, p.130-134, 1995.

PIJNENBORG, JAN W.M., LIE, T.A. Effect of lime on the nodulation of lucerne (Medicago sativa L.) in na acid soil: A comparative study carried out in the field, in pots and in rhizotrons. Plant and Soil, Dordrecht, v.121, p.225-234, 1990

POOLPIPATANA, S., HUE, N.V. Differential acidity tolerance of tropical legumes grown for green manure in acid sulfate soils. Plant and Soil, Dordrecht, v.163, n.1, p. 31-139, 1994.

RECHCIGL, J.E., RENEAU JR., R.B., WOLF, D.D., et al. Alfalfa seedling growth in nutrient solutions as influenced by aluminum, calcium, and $\mathrm{pH}$. Communications in Soil Science and Plant Analysis, New York, v.17, n.1, p.27-44, 1986.

REID, W.S. Influence of lime and calcium:magnesium ratio on alfalfa and birdsfoot trifoil yields. Communications in Soil Science and Plant Analysis, New York, v.27, n.5-8, p.18851900, 1996

SAS INSTITUTE. Sas user's guide: Statistics. Cary : SAS Institute, $1985.956 \mathrm{p}$.

SILVA, D.J. Necessidade de calagem e diferentes relações Ca:Mg para a produção de mudas de eucalipto. Viçosa MG, 1986. 53p. Dissertação (Mestrado em Solos e Nutrição de Plantas) - Curso de Pós-graduação em Solos e Nutrição de Plantas, Universidade Federal de Viçosa, 1986.

SU, C., EVANS, L.J. Soil solution chemistry and alfalfa response to $\mathrm{CaCO}_{3}$ and $\mathrm{MgCO}_{3}$ on an acidic Gleysol. Canadian Journal of Soil Science, Ottawa, v.76, n.1, p.41-47, 1996.

VANCE, C.P., HEICHEL, G.H. Carbon in $\mathrm{N}_{2}$ fixation: limitation or exquisite adaptation. Annual Review of Plant Physiology Plant Molecular Biology, Palo Alto, v.42, p.373-392, 1991.

VETTORI, L. Métodos de análise de solo. Rio de Janeiro: Ministério da Agricultura - EPF, 1969. 24p. (Boletim Técnico).

VINCENT, J.M. A manual for the practical study of the rootnodule bacteria. Oxford and Edinburgh : Blackwell Scientific; London NW1, 1970. 164p. (IPB HANDBOOK $\mathrm{n}^{\mathrm{o}}$.15). 